\title{
Economy Development and Industry Structure in China
}

\author{
Chong-Mei Wang \\ Administration school of Shandong institute of business and technology, Yantai, 264005 China \\ E-mail:Worshipmei7654@163.com
}

\begin{abstract}
The paper studied on the share of GDP by the data from 1994--2012.It is possible to identify three main structural changes in China's economy: the primary (i.e. agriculture), secondary(i.e. industry) and tertiary (i.e. service). China is in the middle stage of industrialization and transforming from the extensive to the intensive. Due to the secondary industrial production is the main force of the economic development and resulting in which environment pressure was very heavy.
\end{abstract}

Keywords-industry structure; economic development; energy consumption; environmental pressure

\section{CHINESE INDUSTRY STRUCTURE CHANGE}

During the 1980s, China's consumption was approximately equal among the primary (i.e. agriculture), secondary (i.e. industry) and tertiary (i.e. service) sectors. There was also a good balance between light (e.g. textiles manufacturing) and heavy (e.g. petroleum exploitation) industry. However, in the earlier part of the 1990s, the construction, chemical and energy industry developed rapidly and in the end of 1990s which the balance was tilted towards heavy industry. Increased urbanization and consumption became the most visible effects of socio-economic development, imposing higher energy demands than during the times when the textile industry was prominent (Rubo, 2002).

Looking at the share of GDP attributed to each of the three sectors, it is possible to identify three main structural changes in China's economy. First, between 1949 and 2002, the Chinese economy depended on the primary and light secondary industry sectors, with primary industry being the main source of GDP. After 2002, the tertiary industry had developed further and a large proportion of the secondary sector had shifted towards heavy industries such as energy and chemical production. Economic growth has since been driven by the growth in the secondary and tertiary sectors (Figure 1). According to Hollis B. Chenery, the change of economic growth mode corresponds to changes in GDP per capita and industrial structure (1961). Compared to the normal industrial structure corresponding to GDP per capita of the 1980s, the proportion of primary industry in China is lower by 1.71 percentage points, and secondary industry higher by 5.31 percentage points. Worse still, secondary industry consumes the most energy and causes most damage to the environment, as its energy consumption accounts for more $70 \%$ of the total.

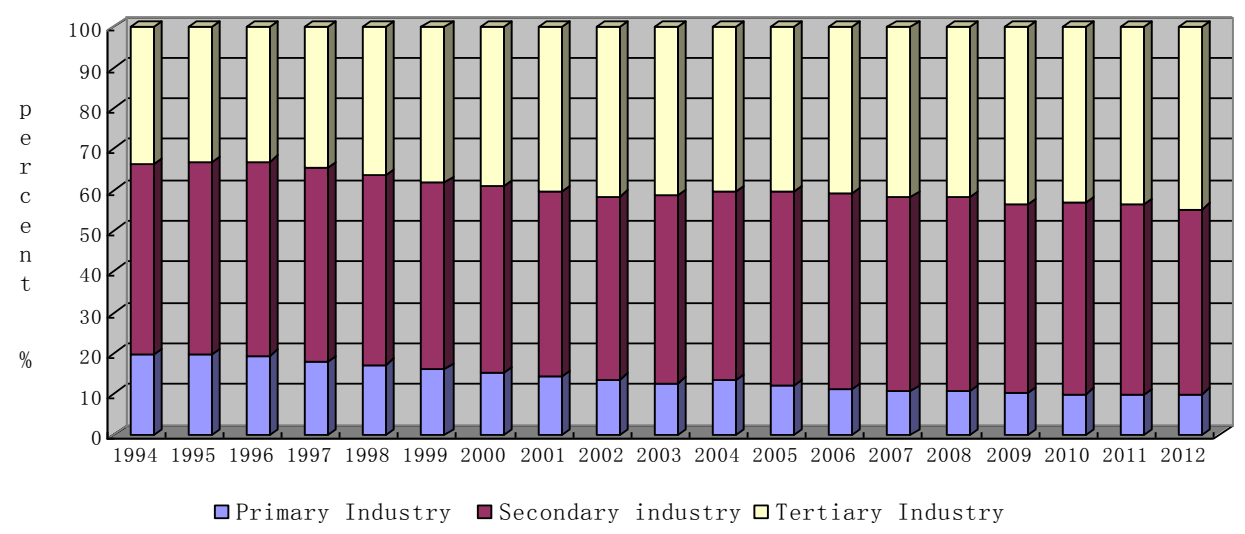

Figure 1. China industrial structure change in 1994-2012

Source: National Bureau of Statistics, China Statistics Yearbook 2013, China Statistics Publishing House

China is in the middle stage of industrialization (Dong, 2006). Secondary industrial production is the main force of the economic development; tertiary industry is quickly growing its share of the GDP. In 2006, the proportion of China's secondary industry in gross domestic product was as high as $48.9 \%$, the tertiary industry only $39.4 \%$, while 
tertiary industry share of GDP in developed countries is generally higher than $70 \% 1$. As secondary industry increases its resource demand, and the proportion of less resource-intensive tertiary industries in China's GDP is low side, the needs of China's economic development for energy and resource are relatively large. At this point, the difficulty of achieving absolute decoupling is very large. Even achieving relative decoupling has also a lot pressure, and still prevents the possibility of re-hook. And China is in the middle stage of urbanization. With China's relatively large population base and the absolute number of annual increasing of the population is great. The original rural population and new population join the cities, increasing the demand for urban housing and other resources, increasing environmental pressures.

\section{TRANSFORMING FROM THE EXTENSIVE TO THE INTENSIVE}

China's economy growth model is transforming from the extensive to the intensive. This shift in the period shows that this shift has not been completed. Currently, China's economy was still dominated by the extensive economy; economic growth also depends mainly on a high investment.

The three factors to promote Chinese Economy, investment, exports and consumption are faced with resource scarcity and environmental pressure. China's current investment is dominated by secondary industry that is related to large energy consumption and emissions. Most of China's investment in the second industry leads to the pressure of the decoupling of economy development in China. China's exports of products can contain quite a lot of energy and emissions. Exports in 2004 total energy consumption account for $28 \%$, while in 2001 only $18 \%$. In 2001 only $6 \%$ in the United States, the European Union 7\%, Japan 10\% (Zhang Yangu, 2004).

\section{ENVIRONMENT PRESSURE}

China's green consumption pattern hasn't been formed yet. Green consumption must consider protecting the "green" as its starting point, without the principle of prejudice to tomorrow's consumption in order to achieve sustainable consumption. The Government, individuals and families, and communities and businesses should have incentives for green consumption behavior, according to the extent of green consumption, as the indicators of future loans, investments, assessment.

The World Bank development report categorized four pollution-intensive industries (see Table I). China's steel, heavy metal, chemistry, construction etc. industries consume $70 \%$ of the total energy produced. According to China Statistics Bureau, among the 40 industries, textiles industry ranks the highest in terms of output value and energy consumption and other high value creating industries such as leather, pharmaceuticals, heavy metal, petroleum, coal mining and beverages, are also heavy users of energy. China's industry structure has put more pressure on the environment, (see Fig.2).

TABLE I. TABLE 1 POLLUTION INTENSIVE INDUSTRIES

\begin{tabular}{cllll}
\hline Rank & Air pollution & Water pollution & Metal pollution & Overall pollution \\
\hline 1 & Steel & Steel & Heavy metal & Steel \\
2 & Heavy metal & Heavy metal & Steel & Heavy metal \\
3 & Non heavy metal & Paper manufacturing & Chemicals & Chemicals \\
4 & Petroleum an coal & Energy products & Leather manufacturing & Oil refinery \\
5 & Paper manufacturing & Chemicals & China production & Non metal mining \\
6 & Oil refinery & Other chemical products & Metal products & Paper manufacturing \\
7 & Chemicals & Beverages & Rubber products & Other chemical products \\
8 & Other chemical products & Food & Electronic products & Rubber products \\
9 & Wood products & Rubber products & Machinery & Leather products \\
10 & Glass products & Oil refinery & Nonmetal mining products & Metal products
\end{tabular}
Source: WB. World Development Report 2008,and http://www.stats.gov.cn/tjsj/ndsj/2014/indexch.htm

\footnotetext{
1 "China's energy situation and policies," the white paper [R]. China Science and Technology Publishing House. Dec, 2007
} 
TABLE II. ENVIRONMENTAL PRESSURES IN 2001-2012 YEAR

\begin{tabular}{|c|c|c|c|c|c|c|c|c|c|}
\hline \multirow[t]{2}{*}{ Year } & \multicolumn{3}{|c|}{$\begin{array}{l}\text { Waste water emission } \\
\text { (1000000tons) }\end{array}$} & \multicolumn{3}{|c|}{ COD emissions $(10,000$ tons $)$} & \multicolumn{2}{|c|}{$\begin{array}{l}\text { Nitrogen and Oxygen } \\
\text { emissions ( } 10,000 \text { tons })\end{array}$} & Compound \\
\hline & Total & Industrial & Residential & Total & Industrial & Residential & Total & Industrial & Residential \\
\hline 2001 & 432.9 & 202.6 & 230.3 & 1404.8 & 607.5 & 797.3 & 125.2 & 41.3 & 83.9 \\
\hline 2002 & 439.5 & 207.2 & 232.3 & 1366.9 & 584 & 782.9 & 128.8 & 42.1 & 86.7 \\
\hline 2003 & 460 & 212.4 & 247.6 & 1333.6 & 511.9 & 821.7 & 129.7 & 40.4 & 89.3 \\
\hline 2004 & 482.4 & 221.1 & 261.3 & 1339.2 & 509.7 & 829.5 & 133 & 42.2 & 90.8 \\
\hline 2005 & 524.5 & 243.1 & 243.1 & 1414.2 & 554.8 & 859.4 & 149.8 & 52.5 & 97.3 \\
\hline 2006 & 536.8 & 240.2 & 296.6 & 1428.2 & 542.3 & 885.9 & 141.3 & 42.5 & 98.8 \\
\hline 2007 & 556.7 & 246.5 & 310.2 & 1381.8 & 511.1 & 870.7 & 132.3 & 34 & 98.3 \\
\hline 2008 & 571.7 & 241.7 & 330 & 1320.7 & 457.6 & 863.1 & 127 & 29.7 & 97.3 \\
\hline 2009 & 589.7 & 234.5 & 355.2 & 1277.5 & 439.7 & 837.8 & 122.6 & 27.3 & 95.3 \\
\hline 2010 & 617.3 & 237.5 & 379.8 & 1238.1 & 434.8 & 803.4 & 120.3 & 27.3 & 93 \\
\hline 2011 & 659.2 & 230.9 & 427.9 & 2499.9 & 354.8 & 938.8 & 264.4 & 28.1 & 147.7 \\
\hline 2012 & 684.8 & 221.6 & 462.7 & 2423.7 & 338.5 & 912.8 & 253.6 & 26.4 & 144.6 \\
\hline
\end{tabular}

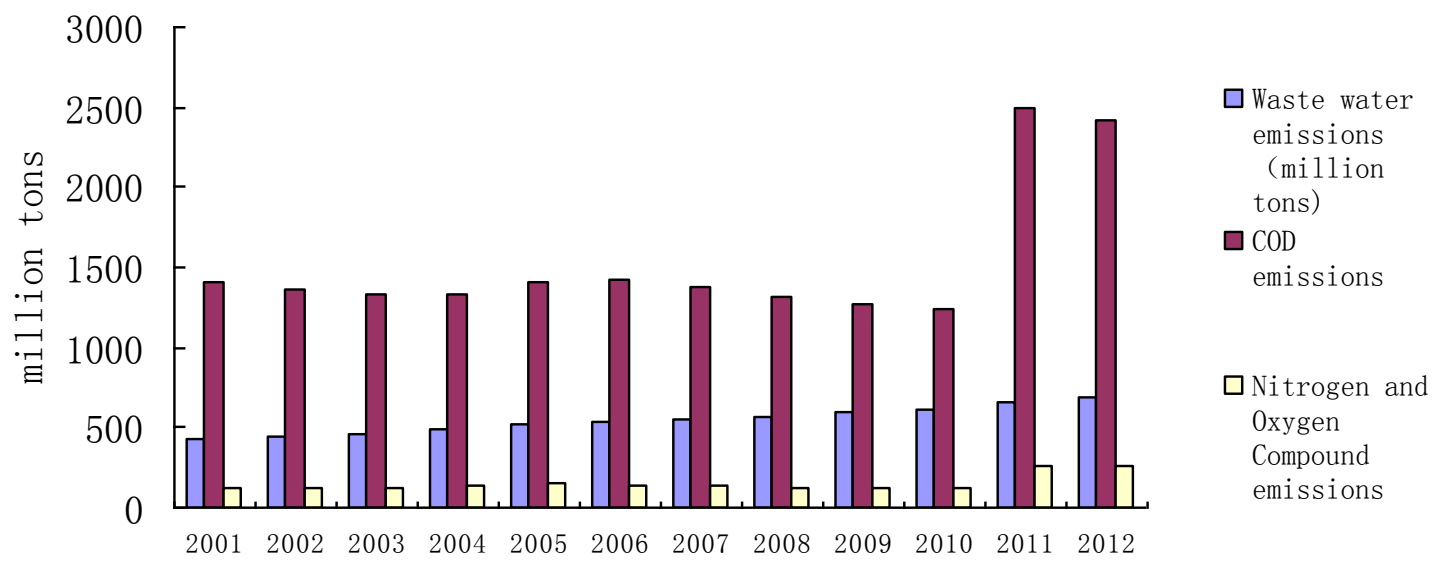

Source: National Bureau of Statistics, China Statistics Yearbook 2013, China Statistics Publishing House 


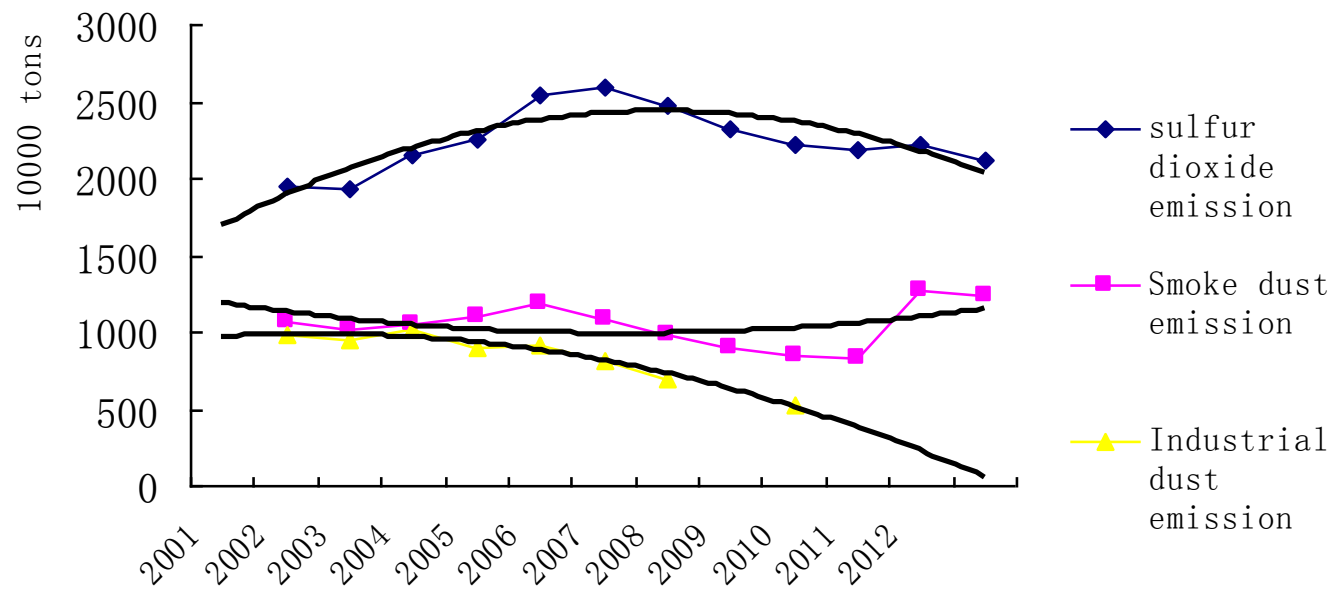

Figure 3. The major air emissions

Source: Figure made with data from the China Environmental Situation Briefing, 2001-2012, Department of National Environmental Protection.

From above Fig. 3, we can come to conclusion that the emission of three major pollutants has increased from 2001 year and they began to decline in 2006.SO2 is the most main pollutant and more double times of others in the air. This shows that fossil fuel is the most of energy during the production process. The smoke dust emission has developed more than industrial dust emission. Smoke dust emission had big development in 2011year.

\section{REFERENCES}

[1] Tang Tianzi, "The circular economy development experience in main developed countries", Research on Financ ia 1 and Econom ic Issues, Number 2 (General SerialNo1255), February, 2005.

[2] National Bureau of Statistics, China Statistics Yearbook 2014, China Statistics Publishing House, http://www.stats.gov.cn/tjsj/ndsj/2014/indexch.htm.

[3] Kong Lingcheng, Study on the industry structure optimation ingrading, Population university of China, 2003.

[4] Cui Rubo, "Constructing green develop system for the development t of green economy", Journal of Yanan University (Social Science), Vol. 24, pp. 2, June, 2002.

[5] B. Chenery,Hollis, "Comparative Advantage and Development Policy. American economic review', Vol.51, No.1, pp.18-51, 1961.

[6] Dong Nan, "Thinking about sustainable development in the middle of industrialization", East china economy management, June 2006. 